\title{
BMJ Open Seeking the balance between caregiving in dementia, family and employment: study protocol for a mixed methods study in Northern Germany
}

\author{
Lydia Neubert, Hans-Helmut König, Christian Brettschneider
}

To cite: Neubert L, König H-H, Brettschneider C. Seeking the balance between caregiving in dementia, family and employment: study protocol for a mixed methods study in Northern Germany. BMJ Open 2018;8:e019444. doi:10.1136/ bmjopen-2017-019444

- Prepublication history for this paper is available online. To view these files, please visit the journal online (http://dx.doi org/10.1136/bmjopen-2017019444).

Received 1 September 2017 Accepted 11 January 2018

Check for updates

Department of Health Economics and Health Services Research Hamburg, University Medical Center Hamburg-Eppendorf, Hamburg, Germany

Correspondence to

Lydia Neubert;

I.neubert@uke.de

\section{ABSTRACT}

Introduction The debate on reconciliation between childcare and working has to be expanded to caregiving for the elderly, since the importance of informal caregiving will increase in the future due to populations' ageing and women's increasing labour force participation. Informal caregivers who are caring for the rising number of persons with dementia $(\mathrm{PwD})$ are often female and subjected to high caregiving requirements. These are added to further demands emerging from their family and work life. How affected caregivers seek to balance those requirements depends on, inter alia, their own characteristics and the informal caregiving network to whom they relate. Both aspects were not yet considered in previous studies. This mixed methods study thus aims to explore the reconciliation between caregiving in dementia, family and employment by including different members of caregiving networks of home-dwelling PwD and by considering their personal characteristics.

Methods and analysis By purposive sampling, we include at least five caregiving networks of home-dwelling PwD; each of them consisting of at least three informal caregivers living in Northern Germany. Narrative interviews of participants will be recorded, transcribed verbatim and interpreted according to the Documentary Method (QUAL). By completing standardised questionnaires, participants will provide sociodemographic and psychographic data concerning themselves and the networks from whom they arise (quan). This supplemental, descriptive information will give further background to the themes and types emerging from the interviews. Hence, the quan-data enrich the QUAL-data by exploring the narratives of participants in the light of their personal and networkrelated characteristics.

Ethics and dissemination Ethical approval was obtained from the Ethics Committee of the German Society of Nursing Sciences. Study results will be disseminated through conference presentations and publications in peer-reviewed journals.

Trial registration number DRKS00012929.

\section{INTRODUCTION}

Family caregivers and other related caregivers of persons with dementia $(\mathrm{PwD})$ are subjected to a higher load than the general population. Because seniors generally prefer

\section{Strengths and limitations of this study}

- This German study will provide insights into a complex topic from a network perspective for the first time.

- Informal caregiving network is composed of familial and non-familial members in this study.

- By merging qualitative and quantitative data, narratives of study participants will be explored considering their sociodemographic and psychographic characteristics and the caregiving network from whom they arise.

- This study will include only five networks consisting of (at least) 15 informal caregivers of persons with dementia; further research should expand the sample size.

- Results may only apply for the German healthcare system and its providers; we appreciate replications in other countries.

living at home, many of them are cared for by their relatives at home as long as possible. ${ }^{1}$ Their caregiving commitments affect their personal and work life considerably. In Germany, the estimated number of elderly or impaired people living in the community who are cared for by their relatives amounted to more than 2 million in 2015. This represents $73 \%$ of all people in certified need of care according to the legal regulations fixed in the Social Security Code XI (Sozialgesetzbuch $X I){ }^{2}$ In many cases of home-dwelling individuals in need of care, more than two informal caregivers are involved, which corresponds to approximately 4-5 million informal caregivers (eg, relatives, neighbours and friends) in Germany. ${ }^{3}$ Focusing on dementia, more than 1.5 million PwD lived in Germany in 2012; this is almost $2 \%$ of the total population, which is higher than the European average of $1.5 \%$. $^{4}$ This number will increase to 3 million by the year 2050 because of the increasing life expectancy and the fact that Alzheimer's disease and related forms of dementia are 
age-associated illnesses. ${ }^{5}$ Therefore, the importance of informal caregiving in dementia care is bound to increase in the future-in Germany and worldwide. ${ }^{6}$

From an economic point of view, the costs of informal care constitute the majority of total societal costs of PwD living in the community. ${ }^{7}$ These costs increase with the progression of dementia and patients' impairments in activities of daily living, need for care and supervision. ${ }^{8}$ Productivity loss (ie, lost workforce) of informal caregivers of PwD should also be considered when measuring societal costs of dementia. In their review, Lilly et at concluded that caregivers, in general, are equally as likely to be in the labour market as non-caregivers but commit fewer work hours to the labour market than non-caregivers; in particular, if the caregiving responsibilities exceed 10 hours per week, the likelihood to withdraw from the labour market also increases.

To take up this evidence and to focus on dementia caregivers, we reviewed the interplay between informal caregiving in dementia and caregiver's employment (Neubert et al, under review). However, we can confirm considerable work impairments of employees with caregiving commitments at home. Besides objectively measured effects like the reduction of work hours or stop working, many caregivers perceive work-caregiving conflicts that stress caregivers' burden in addition to the caregiving requirements. Hence, working full time and having difficulties in balancing work and caregiving tasks predicted caregivers' strain; also, inflexible work conditions predicted depressive symptoms of dementia caregivers. ${ }^{10}$ However, to be a caregiver of a PwD and to be employed also involve positive work experiences and does not necessarily lead to exacerbated caregivers' burden. Moreover, combining unpaid caregiving with a paid job is associated with more happiness for the informal caregivers. ${ }^{11}$

Society is subject to two 'structural mega-trends', namely women's increasing labour force participation and an expected increase of people needing care due to an ageing population. ${ }^{12}$ The labour market participation of female employees is indispensable for the maintenance of societal economic productivity. However, as the majority of informal caregivers is female, ${ }^{3}{ }^{13}$ the existing conflict between caregiving and employment might be further exacerbated. For this reason, political and societal stakeholders should be interested in finding a way to reconcile caregiving and working and to support informal caregivers of an employable age in maintaining their labour market participation without limiting their role in dementia caregiving.

How informal caregivers of $\mathrm{PwD}$ experience balancing care-related, family-related and employment-related requirements depends on different factors (figure 1). First, country-specific legal regulations and structural conditions within the respective long-term care system are relevant. In Germany, for instance, the regulations on Caregiver Leave and Family Caregiver Leave (Pflegezeitgesetz and Familienpflegezeitgesetz) allow family caregivers to take time off work for a specific time period. Employees thus will be given more flexibility and security to temporarily care for their relatives without completely leaving the labour market. ${ }^{14}$ Second, personality traits, which means how an individual evaluates his or her own life and changing circumstances, and coping skills in handling high-load situations considerably influence caregivers' experience. ${ }^{15}{ }^{16}$ In caregiving research, so far, little is understood about how caregivers perform their roles better and why. ${ }^{17}$ Third, professional (paid) services that form the formal caregiving network contribute to the caregiving situation at home by providing information, respite and support, such as day care centres. ${ }^{18}$ Fourth, other (usually unpaid) persons who represent the informal caregiving network contribute to caregivers' perception and can reduce caregivers' burden. However, although the value of a cooperative structure within the family or circle of acquaintances seems to affect caregivers' wellbeing and quality of life, ${ }^{19} 20$ their possible relevance to mediate work-to-care and care-to-work conflicts has rarely been examined. It should be noted that others in the social network might not only be mediating but rather demanding, which we should also consider in the reconciliation debate. Therefore, further research on reconciliation between caregiving in dementia and other roles might include the perspective of more than one person within the family or circle of acquaintances to gain a more comprehensive picture of the caregiving networks' impact. Moreover, a short look at the caregiving network might be not sufficient, because caregiving research delves into a very complex and dynamic phenomenon. It is based on the emotional relationship between a caregiving and cared-for person as well as between different caregivers if caregiving responsibilities are shared. ${ }^{17}$ For instance, by comparing caregiving spouses, adult children and children-in-law, data on outcomes like resources, stressors and psychological distress differ between the groups, so each of them has different needs based on his or her subjective burden and personal circumstances (eg, coresidence with the cared-for person, income and other family responsibilities) ${ }^{21}$ Additionally, caregiver relationships are built on a common descent or by marriage, and they are also influenced by social expectations of family and caregiving varying by culture. ${ }^{22}$ Hence, caregiving research should not ignore personal motives of caregivers if we want to better understand caregiving processes, also, in the light of balancing care-related, family-related and employment-related requirements.

\section{Aim and research questions of the study}

To the best of our knowledge, no study has investigated the reconciliation between caregiving and other roles from a network perspective until now, since studies only considered the primary caregivers' perceptions. Previous studies on this topic also disregarded psychographic characteristics of informal caregivers. Therefore, this mixed methods study aims to explore the reconciliation between caregiving in dementia, family-related and employment-related requirements of informal caregiving 


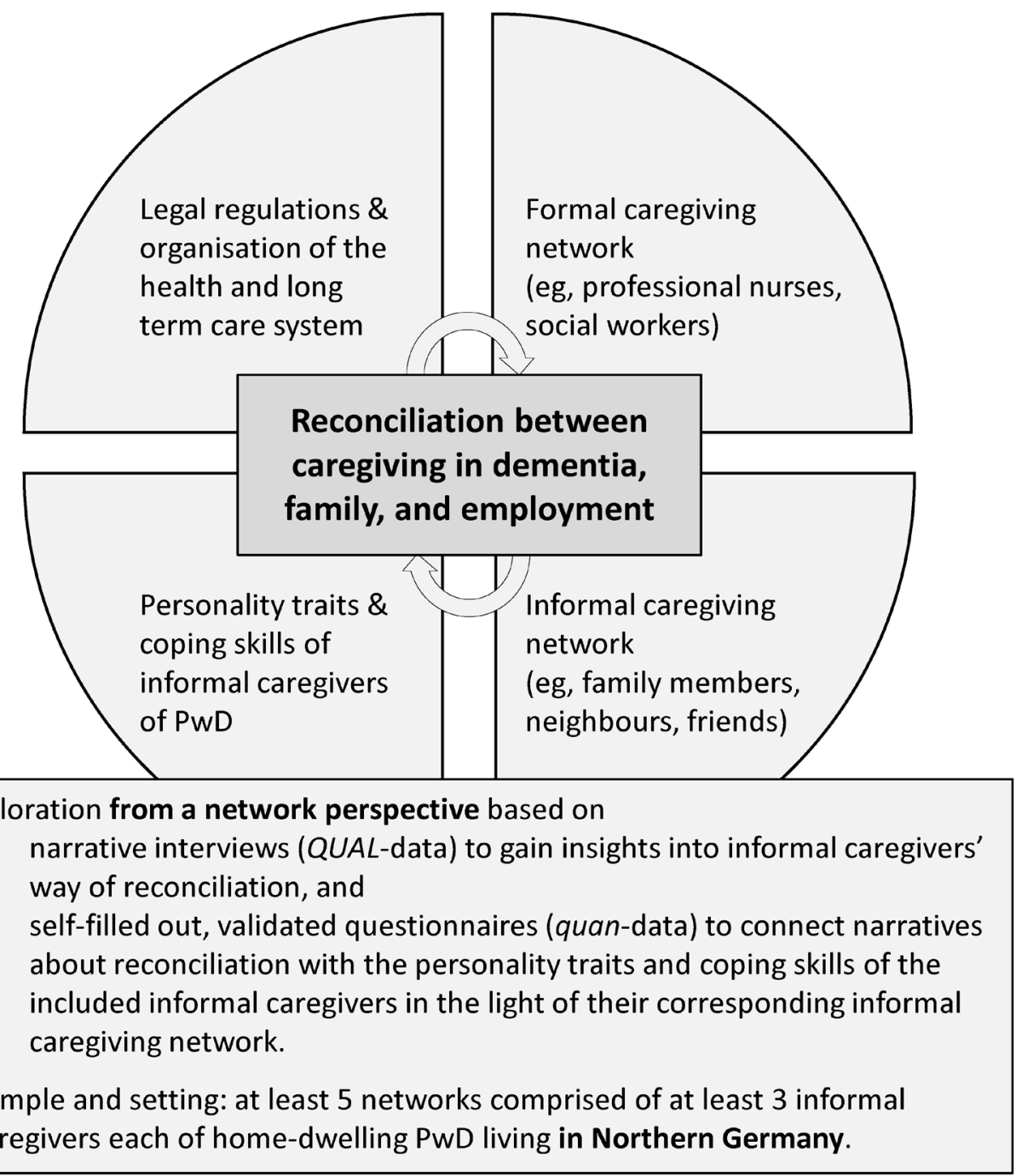

Figure 1 Background and aim of this mixed methods study. PwD, persons with dementia.

network members of $\mathrm{PwD}$ living at home by including at least three familial and non-familial members of each caregiving network. The study focuses on the subjective reconciliation described by the study participants in the qualitative research strand. Thus, the primary question of this study is: how do informal caregivers of PwD experience the reconciliation between caregiving in dementia, family tasks and employment? By merging qualitative and quantitative data, narratives of study participants will be further explored by combining those with their sociodemographic and psychographic characteristics and the caregiving network to whom they relate. Figure 1 outlines the background and aim of this mixed methods study.

To gain a broad picture of the experiences of informal caregivers regarding the reconciliation between caregiving in dementia, family and employment, we formulated the following subordinated research questions.

Within the qualitative research strand, narrative interviews with informal caregivers of $\mathrm{PwD}$ living in Northern Germany with written informed consent will provide answers to the following research questions: how do members of informal caregiving networks experience assuming caregiving responsibilities for an individual with dementia? How do they experience the division of caregiving tasks, that is, who feels responsible for which task and how does she/he experience it? How do they experience possible consequences regarding other commitments and areas of life (eg, child care, work and leisure time) due to caregiving? How do they experience circumstances that may influence the perceived consequences positively or negatively?

The quantitative research strand will explore the evaluation of the life situation of network members according to a standardised approach by measuring caregivers' care-related strain via CarerQol Instrument (CarerQol-7D, CarerQol-VAS) and Zarit Burden Interview (ZBI, 14th+18th item) and measuring caregivers' life satisfaction via $\mathrm{EQ}-5 \mathrm{D}$ Instrument (EQ-5D-5L, EQ-VAS).

Finally, by merging the qualitative and quantitative data at the level of interpretation, we will explore how the 
caregivers' perception-based on the qualitative research strand-and evaluation-based on the quantitative research strand-regarding their current life situation are possibly interrelated with their sociodemographic characteristics, personality traits and coping skills in consideration of the corresponding caregiving network. To measure caregivers' psychographic characteristics, we will apply the Neo-Five-Factors Inventory (NEO-FFI-30), Allgemeine Selbstwirksamkeit Kurzskala (ASKU, short-form of a German self-efficacy scale) and Proactive Coping Inventory (PCI).

\section{METHODS AND ANALYSIS \\ Overview of the study design}

We chose a simultaneous qualitatively driven mixed methods design to apply both qualitative and quantitative methods complementarily (QUAL+quandesign). ${ }^{23}$ After separate data collection and analysis, qualitative data and quantitative data will be combined at the level of interpretation. Qualitative (QUAL) data collection and analysis will be prioritised. For this, we will interview informal caregivers and interpret their narratives to explore their subjective experience of the reconciliation between caregiving in dementia, family tasks and employment. Qualitative inquiry refers to the investigation of underlying knowledge and the understanding of social phenomena. Thus, it aims to understand the meaning of human action. ${ }^{24}$ To gain the personal perspectives of human actors in this study, informal caregivers are invited to tell of their subjective experiences. Their descriptions regarding the perceived reconciliation between caregiving in dementia, family tasks and employment is our leading research interest. It also covers the perceived consequences on the wider family or other related persons, on the subjective health status and quality of life, since they have multiple roles as a caregiver, relative, neighbour or friend and/or an employee. We prioritise the qualitative research strand in this mixed methods study, yet we also appreciate the complementary quantitative approach. In this, we will additionally collect quantitative (quan) data by using validated questionnaires. These will measure caregivers' evaluation of their current life situation, their sociodemographic and psychographic characteristics (ie, personality traits and coping skills). Based on this, narratives of study participants will be explored considering their personal characteristics and the caregiving network to whom they relate.

The next paragraphs describe the methodical procedure in detail. Figure 2 demonstrates the used QUAL+quandesign in this study.

\section{Recruitment of study participants}

In the vast majority of cases of informal caregiving, besides the main or primary caregiver (ie, the individual with the greatest care responsibilities), further persons are involved in a smaller or larger degree. For example, a husband of a caring daughter, who supports his spouse in the decision-making procedure regarding the care of his mother-in-law or even if he lends an ear to his wife,

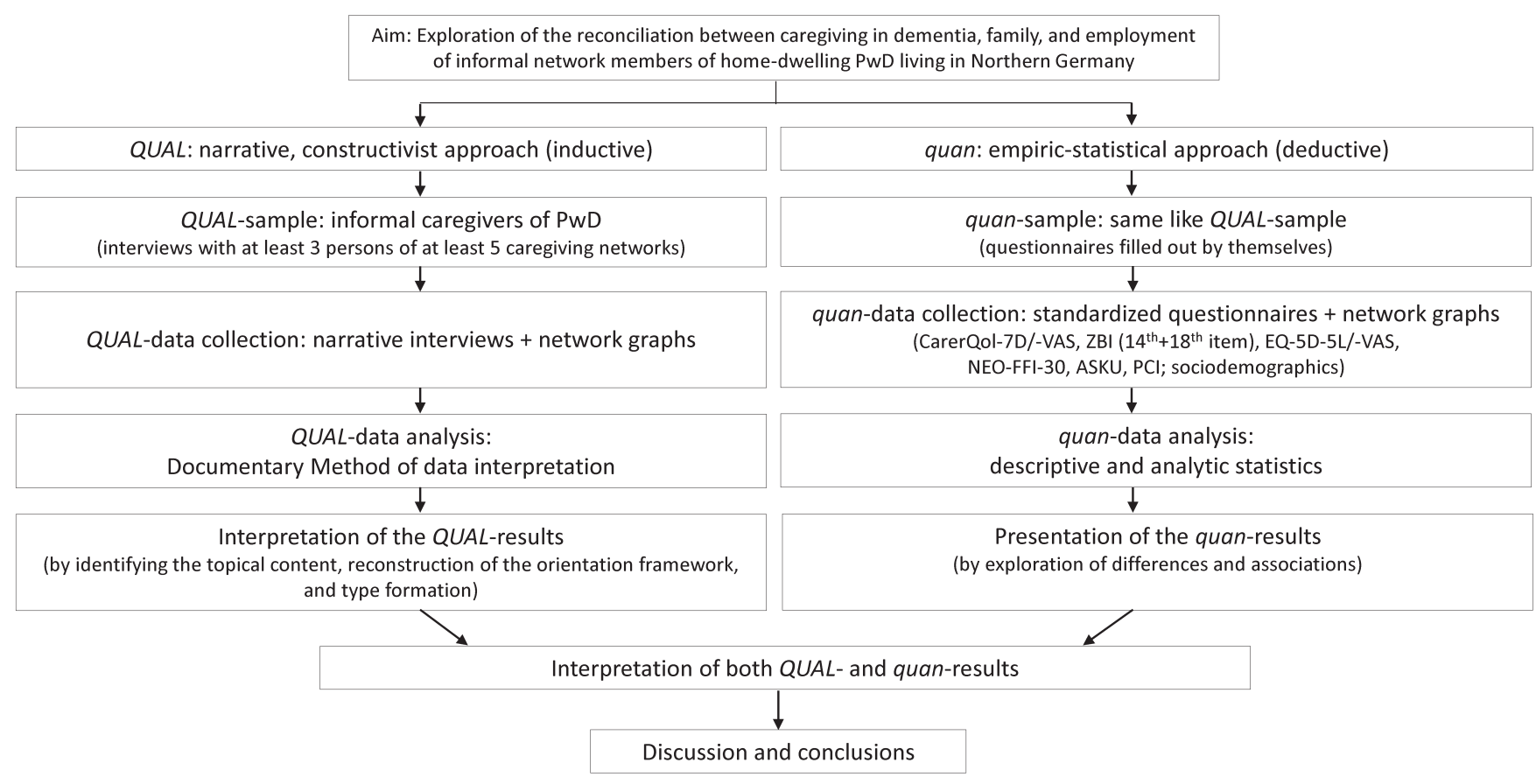

Figure 2 Simultaneous qualitatively driven mixed methods design (QUAL+quan design). ASKU, Allgemeine Selbstwirksamkeit Kurzskala (only available in German); CarerQol-7D/NAS, CarerQol Instrument (German version); EQ-5D/VAS, EQ-5D Instrument (German version); NEO-FFI-30, Neo-Five-Factors Inventory (German version); PCI, Proactive Coping Inventory (German version); PwD, persons with dementia; ZBI, Zarit Burden Interview (German version). 
is an involved caring person. So, caregiving in general and in dementia mainly affects the primary caregiver and further individuals who build the caregiving network.

Koehly et $a l^{25}$ used a multi-informant social network approach to investigate caregiving processes within the context of Alzheimer's disease and related dementia. As a result, they suggest that a sampling approach with at least three informants allows a more comprehensive assessment of a family caregiving network. In our study, we broadened the perspective by including non-familial individuals like neighbours or friends as well.

The first step of recruitment was to personally contact gatekeepers engaged in counselling centres for seniors and family caregivers (Pflegestützpunkte) or self-help groups (eg, affiliated with the Alzheimer Gesellschaft Hamburg e.V.) located in Hamburg, Schleswig-Holstein and Lower Saxony. By addressing different gatekeepers in different regions of Northern Germany, we were able to broaden the possibilities to come in contact with eligible study participants and to reduce sampling bias. There, the main researcher (LN) displayed the study information covering the aims and procedures of the study, the inclusion criteria to select study participants, data collection, processing and storage, as well as participants' contribution to this work and the possibilities for opting out. Furthermore, she visited these service points to inform both gatekeepers and potential study participants face to face. Within these visits, she informed the gatekeepers comprehensively about the inclusion and exclusion criteria to avoid unsuitable preselection of clients. All potential study participants had time to read and fully understand both the study information and declaration of consent. In case of ambiguities, the main researcher was present to answer all emerging questions. Because study information contains the researcher's telephone number, mailing address and email address, potential study participants can contact her during office hours to ask questions and receive further oral information about the study.

In this way, we expect that the first informal caregiver of a caregiving network of a home-dwelling PwD will be admitted. This individual is the index interviewee who also provides access to at least two other informal caregivers of each network. Each of them has to be involved in care, support those involved in care or could be involved due to their relationships with the cared-for individual with dementia. The index interviewee has to give written permission before being interviewed and will name at least two other network members who had agreed to participate. Already at that time or at their own interviews at the latest, the interviewer (LN) will obtain the declarations of consent of the additional network members. Appointments for the interviews will be arranged by the interviewer. She will contact named network members approximately 1 week after the index interview. This sampling approach will be continued until the desired number of at least three network members (including the index interviewee) is reached. The number of persons who refuse to participate and their reasons for opting out will be documented in the study diary.

\section{Sample size and eligibility criteria of study participants}

In total, (at least) five networks consisting of (at least) 15 informal caregivers of $\mathrm{PwD}$ will be included in this study through purposive sampling to reach maximum variation between characteristics of the study participants (eg, gender, age, relationship to the cared-for person and living situation). The sample size is restricted by the feasibility of this study; that is, the target sample size is explained by the explorative character of this study that is a preparatory part of a larger study. However, qualitative data analysis requires contrasting cases, whereby further sampling can be necessary until this goal will be achieved (see paragraph 'qualitative data analysis'). If potential study participants refuse or withdraw study participation, the research team will replace them. If participants withdraw or refuse to participate —after they were nominated by the index interviewee-and cannot be replaced, the index interviewee's data are be considered as individual data. This means, their interpreted narrations and analysed data are relevant for the aggregated results but cannot contribute to the interpretations from the network perspective. Following Koehly et $a l^{25}$ we determined the following inclusion criteria:

- Members of the informal caregiving network are individuals who are important for care delivery to the affected person with dementia or the first informal caregiver (index interviewee); that is, they undertake caring tasks (eg, personal care and eating), household tasks (eg, cleaning and cooking), support in the care-related or everyday decision making and/ or emotional support during the caregiving period. The degree of involvement in caregiving and both the relationship to the individual with dementia and the living situation (living together with the cared-for person or not) are not relevant for study inclusion. For instance, an eligible caregiving network can comprise a retired wife caring for her husband with dementia, a daughter of employment age-not living with her parents, with her own family commitments and supporting her mother in decision making and visits to medical professionals or authorities-and a volunteer who supervise the cared-for person once a week for a few hours.

- Members of the informal caregiving network (1) are older than 18 years, (2) have appropriate German language skills and no cognitive impairments to conduct the interview, (3) are living in an urban or adjacent region of Hamburg, or an urban or rural region of Schleswig-Holstein or Lower Saxony (within a maximum linear distance of $100 \mathrm{~km}$ from our department in Hamburg) and (4) at least one member of each participating caregiving network is employed at the time of investigation. Since many caregivers are old themselves and already retired, ${ }^{21}$ only employed (younger) caregivers will be asked 
how they experience the reconciliation between their caregiving and work responsibilities (whether their contributions in caregiving are small or large; that is, these network members do not need to be the primary caregivers).

- The first member of the informal caregiving network verbally confirms the presence of the Alzheimer's disease or related dementia of the cared-for person and its functional impairments according to the Social Security Code XI (Sozialgesetzbuch XI). The individual with dementia has to be living at home. Informal caregivers of institutionalised individuals will be excluded. Neither the stage of the disease nor whether the diagnosis was medically confirmed are relevant for inclusion. By ethical reasons, we decided to not collect declarations of consent of PwD. Therefore, we cannot directly request any data concerning the care recipient with dementia while interviewing his/her caregivers. However, it will be essential that the interviewees disclose more or less comprehensive descriptions of the physical and mental constitution of the cared-for person in their own words to illustrate their caregiving situation at home including, for example, their self-perceived burden due to the specific needs of an individual with dementia. Caregivers' perceptions and meanings meet our primary research interest, and additional data like the described functional impairments of the $\mathrm{PwD}$ will likely help us to contextualise the findings.

Recruitment of study participants started in October 2017, and first results are expected in 2018. The study is a preparatory part of a larger project (funded by the German Federal Ministry of Education and Research; grant: 01EH1601A) that ends in August 2020; then, results of this study will be published.

\section{MEASURING INSTRUMENTS}

\section{Qualitative data collection}

For QUAL-data collection, we chose narrative interviews to elicit stories of experiences in accordance with Schütze ${ }^{26}$ and Flick ${ }^{27}$. At the beginning of each interview conducted face to face, an initial question will be stated that encourages interviewees' narration. At best, the interviewer (LN) must not intervene at any time except with encouraging phrases like 'And then?' or nodding as a non-verbal sign of empathic listening. To standardise interviewing, an interview guide was developed and pretested. For this, each question was first discussed between the main investigator (LN) and professor Nohl from the Helmut Schmidt University in Hamburg, who considerably developed the interpretation of narrative interviews by means of the Documentary Method, ${ }^{28}$ then we tested the interview guide in a workgroup of qualitative methods located at the University Medical Center Hamburg-Eppendorf. Participants were asked to provide feedback regarding the comprehensibility of questions; no amendments were necessary after this pretest. If the narrative continuity stagnates, maintenance questions and requests were also narratively formulated. An exemplary, narratively formulated request is 'Please tell me about your last week, day after day. I'm interested in every detail that you did for [the person with dementia]. Let's start with last [Monday]'. Non-narratively formulated requests at the end of the interview can refer to information that still did not occur in the narratives of the interviewees; for example, 'How many hours are you currently working?'. Each interview will close with the invitation to complete a network graph consisting of concentric circles to draw all network members who are important to the interviewee. Used network graphs have an intermediate position between the qualitative and quantitative data (concerning the interpretation of those we refer to the paragraph 'quantitative data analysis'). The theoretical framework, to which the development of the interview guide is subject, is based on a topic-specific literature search (Neubert et al, under review) and on both studies of Koehly $e t a l^{25}$ and Gröning and Kunstmann, ${ }^{29}$ who understand (dementia) caregiving as an informal network task or family task. The main investigator (LN) will conduct all interviews. She is trained in applying qualitative research methods in general and, in particular, in interviewing informal caregivers because of another qualitative study. ${ }^{30}$ She is also aware of the specific life situation of caregivers due to her previous experience as a registered nurse, and she interacts with them empathetically.

\section{Quantitative data collection}

To measure quan-data, we will use questionnaires (10 pages) that will be filled out by the study participants themselves. Each questionnaire initially queries sociodemographic characteristics of the study participants including age, gender, relationship to the cared-for person with dementia, employment status, occupation, living situation and region. These data facilitate descriptions of the sample of this study and hint at the generalisability of the sample. Then, to measure care-related strain, life satisfaction and psychographic characteristics of the study participants, the questionnaire comprises the following validated questionnaires: the German version of the CarerQol-7D, CarerQol-VAS, items no. 14 and 18 of the ZBI, German version, the German version of the EQ-5D-5L, EQ-VAS, the Neo-Five-Factors Inventory (NEO-FFI-30), the short-form of the perceived self-efficacy scale (ASKU) and the German version of the Proactive Coping Inventory (PCI). After its development, the questionnaire was also pretested; for this, we have asked different colleagues to complete the questionnaire while the time needed was measured.

Figure 3 gives an overview about the schedule of study participation in this study.

To realise interviews and measurements, study participants can choose between a visit at home by the main researcher (LN) or a meeting at the Department of Health Economics and Health Services Research. In the latter case, insurance covers possible accidents on the way 


\begin{tabular}{|c|c|c|c|}
\hline Written informed consent & $\begin{array}{l}\text { Appointment for } \\
\text { interviewing }\end{array}$ & $\begin{array}{l}\text { Interview } \\
-\quad \text { narrative interviews }\end{array}$ & $\begin{array}{l}\text { Pseudonymisation and } \\
\text { analysis of data }\end{array}$ \\
\hline & & $\begin{array}{ll} & \text { (recorded and transcribed) } \\
- & \text { network graphs } \\
- & \text { self-filled out questionnaires }\end{array}$ & \\
\hline
\end{tabular}

Figure 3 Overview of study participation. PwD, persons with dementia.

to or from the research department, and travel costs are repaid. In general, it is important that the interviews will be undisturbed; that is, a meeting room is reserved, and colleagues are asked for consideration. If study participants wished to be interviewed as a couple or a group, we would accept this; however, our intention is that each study participant should have the equal opportunity to respond freely. If study participants did not wish to visit the research department or to be interviewed at home, we would also arrange interviews via telephone or Skype. We calculate that each narrative interview will last 1-2 hours followed by answering the questionnaire. To diminish the study participants' burden, it is possible for them to complete the questionnaires later. In this case, the main researcher (LN) will give them a stamped envelope accompanied by a reminder to contact her if any questions arise while completing the questionnaire. For this, we originally estimated a duration of 30-45 min, but we observed shorter periods in some pretests. Each study participant will receive an expense allowance (ie, a sum of money in euros) after completing both measurements.

\section{DATA ANALYSIS}

\section{Qualitative data analysis}

The interviews will be recorded and transcribed verbatim. We chose the Documentary method of data interpretation in accordance with Arnd-Michael Nohl ${ }^{28}{ }^{31}$ to analyse and interpret the textual material of the narrative interviews. This method aims to reconstruct the practical experiences of individuals, social groups, milieus or organisations (referred to as the orientation framework) to obtain access to their orientations of action that are visible in their everyday lives. Narratives are preconditions to reconstruct the orientation framework; the chosen form of interviewing is thus suitable, since the provided textual material should consist of impromptu narratives, even if the interviewees' narratives will be, of course, linked with descriptions and argumentations. The researcher's interest refers to the way a narrative text or action is constructed by the interviewee or how the limits within which its topic are dealt with, that is, the orientation framework within which a topic or problem is handled. ${ }^{31}$ In practice, the Documentary Method comprises three stages of interpretation: formulating interpretation (to summarise topics), reflecting interpretation (to generate the framework of orientation, in which the topics are elaborated on) and type formation (ie, the emerged empirical results become visible as types) ${ }^{28}$ From the beginning of the three-staged interpretation process to its end, the Documentary Method is based on a consistent comparative analysis. For this, the orientation framework is generated by comparing one case (interview sequence) with other empirical cases (interview sequences) that deal with the same topic but within contrasting orientation frameworks. For instance, if we only look at one interview sequence, we would interpret it against the background of our own (or common) theories regarding the topic of interest. By comparing this first with other interviews (sequences), both our knowledge and interpretation is methodically relativised. In this way, Nohl declares the comparative analysis as the golden standard of methodically controlled research. ${ }^{28}$ In this study, each informal caregiver provides text (sequences) related to the common topic, and by comparing this (these) with text (sequences) of another informal caregiver, the orientation framework emerges. Following the formulating and reflecting interpretation, different approaches of type formation (sensegenetic, sociogenetic or relational ${ }^{32}$ ) lead to generalisation of the empirical results by identifying similar or overlapping cases based on case comparisons.

Data analysis will be conducted after each interview from the beginning of the data collection process by the main investigator (LN) and a research assistant on the bachelor level. Because of the comparative analysis within the Documentary Method, further characteristics, that is, themes, will be used as varying factors during the interpretation and may provoke resampling to recruit further study participants who may provide heterologous themes. Thought processes and decision trails during data analysis and subsequent interpretations will be documented, and interpretations will be discussed with the project leader (CB) and another member of the workgroup. Furthermore, attendance of an interpretation group working with the Documentary Method located at the University of Hamburg will also be used to validate the interpretation. Interpretation will be supported by MAXQDA (V.12).

\section{Quantitative data analysis}

Regarding the quantitative data analysis, the questionnaires named above serve to explore the identified care-related strain (CarerQol-7D and ZBI) and the evaluation of the life satisfaction (CarerQol-VAS and EQ-5D$5 \mathrm{~L} / \mathrm{VAS}$ ) of the study participants with consideration of their personality traits (NEO-FFI-30 and ASKU) and coping skills (PCI). Data from completed questionnaires 
will be transferred into datasets. With descriptive statistical methods including frequency and contingency analysis, we will describe the sample of informal caregivers included in this study. Using analytic statistical methods (ie, correlational analysis by calculating Pearson's correlation coefficient $r$ or Spearman's rank correlation coefficient $\rho$ ), we will explore possible associations of care-related strain and personality traits or coping skills variables. We will also examine if topics or types emanating from the qualitative data analysis could be used as variables that may also be associated with the personality traits variables, for example. Furthermore, using a regression model by applying care-related strain (measured by the CarerQol-7D) as outcome variable, we will generate an equation to describe the statistical relationship between this outcome and predictor variables based on the quan-data. These results will be interpreted with great caution due to the small sample size. All analyses will be supported by the feature 'Stats' of MAXQDA (V.12) and IBM SPSS Statistics (V.23). Because of prioritisation of the QUAL-approach in this mixed methods study, the quan-data are supplemental to enrich the QUAL-data by exploring the narratives of study participants in the light of their personal characteristics named above and the network to whom they relate. Network graphs present the number of network members and their degree of importance from the personal perspective of the respective network member. Additionally, combined with the narratives of those, caregiving tasks of each network member are described. So, the quan-data may enhance the profiles of included caregivers in this study and can serve-due to the small sample size-at least as a starting point for further research in this field.

This study considers personal and network-related characteristics of informal caregivers of $\mathrm{PwD}$ for the first time; in this way, we hope to meet the relevance of these factors in caregivers' experience of the reconciliation between caregiving in dementia, family and employment.

\section{Ethics, data protection and dissemination}

The study is registered in the German Clinical Trial Register (DRKS), DRKS00012929. Furthermore, the study was planned in accordance with the German Federal Data Protection Act (Bundesdatenschutzgesetz) and the Data Protection Law of Hamburg (Hamburger Datenschutzgesetz) and will be processed under the guidance of the data protection officer of the conducting research department.

Study participants have to give written informed consent before data collection. By using audio records and (paper) questionnaires, data will be collected. All data will be pseudonymised; thus, qualitative (interview) data and quantitative (questionnaire) data will be combined at the level of interpretation. When data collection is finished, the key list (assignment of study participants' names to pseudonyms) and the mailing addresses of the study participants will be destroyed in accordance to data protection regulations. Audio records of the interviews will be deleted after transcription. Data of the questionnaires will be transferred into datasets that will only be available to the main researcher (LN) who will store the datasets in her password-protected computer. Declarations of consent and pseudonymised data will be stored separately in locked cabins within secure offices for 10 years after the end of the study.

The results of this study will be presented at scientific conferences in Germany and beyond and will be published in peer-reviewed, national and international, journals.

\section{Expected impact of the study}

By including different familial and non-familial members of caregiving networks, we will be the first to explore the reconciliation between caregiving in dementia, family-related and employment-related requirements of informal caregiving in dementia at a national level. The network perspective will provide more detailed insights into this complex topic than an ego-centred perspective. By merging qualitative and quantitative data, the narrated ways of reconciliation will be investigated in consideration of the sociodemographic characteristics, personality traits and coping skills of each informal caregiver and in the light of the corresponding caregiving network.

The methodological approach used serves as a starting point for further research in this field, for instance, by including a larger sample of affected informal caregivers of $\mathrm{PwD}$ or applying further methods of network analysis. Our results will help policymakers and stakeholders regarding healthcare, social issues, labour force and economics to understand better how informal caregivers of $\mathrm{PwD}$ are subjected to the requirements of their everyday lives, how they are seeking to balance these requirements and which interventions can support them to fulfil their major role in dementia caregiving in our society.

Contributors LN was responsible for the original idea, literature review and study design. $\mathrm{H}-\mathrm{HK}$ and $\mathrm{CB}$ advanced the concept. All authors contributed to obtaining the ethical approval. LN drafted this manuscript; $\mathrm{H}-\mathrm{HK}$ and $\mathrm{CB}$ reviewed it critically. All authors read and approved the final manuscript.

Funding This study is funded by the German Federal Ministry of Education and Research (grant: 01EH1601A). The funding source takes no part in the collection, analysis and interpretation of data, in the writing of the manuscript or in the decision to submit the manuscript for publication.

Competing interests None declared.

Patient consent Not required.

Ethics approval Ethical approval for this study was obtained from the German Society of Nursing Sciences (approval no. 17-006).

Provenance and peer review Not commissioned; externally peer reviewed.

Open Access This is an Open Access article distributed in accordance with the Creative Commons Attribution Non Commercial (CC BY-NC 4.0) license, which permits others to distribute, remix, adapt, build upon this work non-commercially, and license their derivative works on different terms, provided the original work is properly cited and the use is non-commercial. See: http://creativecommons.org/ licenses/by-nc/4.0/

(c) Article author(s) (or their employer(s) unless otherwise stated in the text of the article) 2018. All rights reserved. No commercial use is permitted unless otherwise expressly granted. 


\section{REFERENCES}

1. Kuhlmey A, Suhr R, Blüher S, et al. [Das Risiko der Pflegebedürftigkeit. Pflegeerfahrungen und Vorsorgeverhalten bei Frauen und Männern zwischen dem 18. und 79. Lebensjahr]. In: Böcken J, Bernard B, Repschläger U, eds. Gesundheitsmonitor 2013 Bürgerorientierung im Gesundheitswesen Kooperationsprojekt der Bertelsmann Stiftung und BARMER GEK. Gütersloh: Bertelsmann Stiftung, 2013:11-38.

2. Statistisches Bundesamt. Pflegestatistik 2015. Pflege im Rahmen der Pflegeversicherung - Deutschlandergebnisse. Wiesbaden: Statistisches Bundesamt, 2017.

3. Wetzstein M, Rommel A, Lange C. [Pflegende Angehörige - Deutschlands größter Pflegedienst]. GBE kompakt 2015; 3 https://www.rki.de/DE/Content/Gesundheitsmonitoring/ Gesundheitsberichterstattung/GBEDownloadsK/2015_3_pflegende_ angehoerige.html.

4. Alzheimer Europe. The prevalence of dementia in Europe (Germany 2013). http://www.alzheimer-europe.org/Policy-in-Practice2/Countrycomparisons/2013-The-prevalence-of-dementia-in-Europe/Germany (accessed 15 Jan 2017).

5. Doblhammer G, Fink A, Fritze T, et al. The demography and epidemiology of dementia. Geriatric Mental Health Care 2013;1:29-33.

6. Livingston G, Sommerlad A, Orgeta V, et al. Dementia prevention, intervention, and care. The Lancet 2017;390:2673-734.

7. König $\mathrm{HH}$, Leicht $\mathrm{H}$, Brettschneider $\mathrm{C}$, et al. The costs of dementia from the societal perspective: is care provided in the community really cheaper than nursing home care? J Am Med Dir Assoc 2014;15:117-26.

8. Leicht H, König H-H, Übersicht E. [Krankheitskosten bei Demenz]. Bundesgesundheitsblatt 2012;55:677-84.

9. Lilly MB, Laporte A, Coyte PC. Labor market work and home care's unpaid caregivers: a systematic review of labor force participation rates, predictors of labor market withdrawal, and hours of work. Milbank Q 2007:85:641-90.

10. Wang YN, Shyu YI, Chen MC, et al. Reconciling work and family caregiving among adult-child family caregivers of older people with dementia: effects on role strain and depressive symptoms. J Adv Nurs 2011;67:829-40.

11. van Campen $\mathrm{C}$, de Boer $\mathrm{AH}$, ledema J. Are informal caregivers less happy than noncaregivers? Happiness and the intensity of caregiving in combination with paid and voluntary work. Scand J Caring Sci 2013;27:44-50.

12. Kröger T, Yeandle S. Combining paid work and family care. Policies and experiences in international perspective. Bristol: Policy Press, 2013.

13. Colombo F, Llena-Nozal A, Mercier J, et al. Help wanted? Providing and paying for long-term care, OECD Health Policy Studies: OECD Publishing, 2011.

14. Federal Minister for Family Affairs SC, Women and Youth. Better reconciliation of family, care and work. New statutory provisions since 1 January 2015. Berlin: Federal Minister for Family Affairs, Senior Citizens, Women and Youth, 2016.

15. Chen HM, Huang MF, Yeh YC, et al. Effectiveness of coping strategies intervention on caregiver burden among caregivers of elderly patients with dementia. Psychogeriatrics 2015;15:20-5.
16. Gilhooly KJ, Gilhooly ML, Sullivan MP, et al. A meta-review of stress, coping and interventions in dementia and dementia caregiving. BMC Geriatr 2016;16:106.

17. Ornstein KA. Broadening our understanding of caregiver outcomes across cultures: What does "caregiver relationship" actually capture? $J$ Womens Health 2017;26:3-4.

18. Tretteteig S, Vatne S, Rokstad AM. The influence of day care centres for people with dementia on family caregivers: an integrative review of the literature. Aging Ment Health 2016;20:450-62.

19. Vellone $\mathrm{E}$, Piras $\mathrm{G}$, Venturini $\mathrm{G}$, et al. The experience of quality of life for caregivers of people with Alzheimer's disease living in Sardinia, Italy. J Transcult Nurs 2012;23:46-55.

20. Jones C, Edwards RT, Hounsome B. Qualitative exploration of the suitability of capability based instruments to measure quality of life in family carers of people with dementia. ISRN Family Med 2014;2014:1-9.

21. Pinquart M, Sörensen S. Spouses, adult children, and children-in-law as caregivers of older adults: a meta-analytic comparison. Psychol Aging 2011;26:1-14.

22. Lee J, Sohn BK, Lee H, et al. Impact of Behavioral Symptoms in Dementia Patients on Depression in Daughter and Daughter-in-Law Caregivers. J Womens Health 2017;26:36-43.

23. Creswell JW. Mixed Methods Procedures. Research Design: Qualitative, Quantitative, and Mixed Methods Approaches. Los Angeles: SAGE Publications, 2014:215-40.

24. Schwandt TA. Qualitative inquiry. The SAGE dictionary of qualitative inquiry. 3 edn. Los Angeles: SAGE Publications, 2007:247-9.

25. Koehly LM, Ashida S, Schafer EJ, et al. Caregiving networks-using a network approach to identify missed opportunities. J Gerontol B Psychol Sci Soc Sci 2015;70:143-54.

26. Schütze F. [Zur Hervorlockung und Analyse von Erzählungen thematisch relevanter Geschichten im Rahmen soziologischer Feldforschung: dargestellt an einem Projekt zur Erforschung von kommunalen Machtstrukturen]. In: Weymann A, Soziologen AB, eds. Kommunikative Sozialforschung: Alltagswissen und Alltagshandeln, Gemeindemachtforschung, Polizei, politische Erwachsenenbildung. München: Fink, 1976:159-260.

27. Flick U. [Das episodische Interview]. In: Oelerich G, Otto H-U, eds. Empirische Forschung und Soziale Arbeit. Wiesbaden: Verlag für Sozialwissenschaften, Springer Fachmedien, 2011:273-80.

28. Nohl A-M. Narrative Interview and Documentary Interpretation. In: Weller W, Bohnsack R, Pfaff N, eds. Qualitative analysis and documentary method in international educational research. http:// nbn-resolving.de/urn:nbn:de:0168-ssoar-3172532010:195-218.

29. Gröning K, Kunstmann AC. [Sorge für die alten Eltern und familiale Entwicklung. Eine kritische Betrachtung der sozialrechtlichen und wissenschaftlichen Diskurse zur Situation der pflegenden Familie]. In: Bauer A, Gröning K, eds. Gerechtigkeit, Geschlecht und demografischer Wandel: Frankfurt a.M.: Mabuse-Verlag, 2008:89-133.

30. Neubert L. ["Du hast keine Kraft mehr, so von innen kommt nichts mehr "- Das Erleben von Angehörigen während des Wartens auf einen Pflegeheimplatz]. Pflegewissenschaft 2016;3/4:164-79.

31. Nohl A-M. Interview und Dokumentarische Methode: Anleitungen für die Forschungspraxis. 5 edn. Wiesbaden: Springer VS, 2017.

32. Nohl A-M. Relationale Typenbildung und Mehrebenenvergleich. Neue Wege der dokumentarischen Methode. Wiesbaden: Springer VS, 2013. 